of information. The smallest contribution, by Dresch of Paris, deals with the prevalence of iron deficiency in France and contains about 350 words.

One aspect of the subject, about which various workers are not in agreement, concerns the factors that affect iron $a b$ sorption, and particularly the importance or otherwise of gastroferrin. This is referred to and discussed by various workers.

In summing up the views expressed at this excellent symposium, Carl Moore makes the important point that, unlike man, many experimental animals absorb ferric and ferrous iron equally well. $\mathrm{He}$ refers, too, to the degree of sophistication of ferrokinetic studies and how studies of iron absorption have been facilitated by the development of whole body counters. RONALD GIRDWOOD

\section{Nematodes in Action}

The Behaviour of Nematodes: Their Activity, Senses and Responses. By Neil A. Croll. Pp. ix +117. (Arnold: London, November 1970.) $£ 2.25$.

THE author has collected the scattered information about the behaviour of animal, plant and free living nematodes and presented it as a review for research workers and students. The book is mostly about movement and the responses of nematodes to external stimuli ; descriptions of many behaviour patterns such as feeding are omitted. Nematode responses are discussed in individual sections each devoted to a stimulus type, light, temperature, chemical, electric, gravitational and mechanical. Other sections describe movement activity, aggregation and orientation. Most relevant papers seem to be included in the bibliography, and the book is a useful source of references for further study. There are indices to both subjects and species.

The style is pleasant and the text readable although occasionally verbose and vague, or so brief that an idea is not fully defined and statements appear contradictory. A few words are misused and some jargon introduced but less than in many scientific publications. Often Croll has been shy about using his experience to guide readers so that after reading his summary of published work we have to draw our own conclusions and decide where further research is needed. He has, however, introduced new ideas into some sections deriving information from work on animals other than nematodes.

The index is adequate but has several pagination errors and omissions. Some indication of the pages where a subject is discussed in detail would help the reader, but printing and proof reading errors are few.

$$
\text { C. D. GREEN }
$$

\section{Molecular Spectroscopy}

Physical Chemistry: An Advanced Treatise. Vol. 4: Molecular Properties. Edited by Henry Eyring, Douglas Henderson and Wilhelm Jost. Pp. xix + 832. (Academic: New York and London, September 1970.) $£ 18.20$.

THIS volume contains fourteen chapters written by a number of authors. There is an introduction by $\mathrm{S}$. H. Bauer to the various topics covered, which include molecular rotation by C. C. Costain, vibrations of molecules by G. W. King and vibrational spectra by $\mathbf{J}$. R. Hall. Radical spectra are covered by D. E. Milligan and H. E. Jacox, and T. Shimanouchi writes on molecular force fields. The interactions between electronic, vibrational and rotational motions, and the electric moments of molecules are considered by $\mathbf{J}$. T. Hougen and A. D. Buckingham respectively. There are accounts of nuclear magnetic resonance (R. M. Golding), electron spin resonance (H. G. Hecht), nuclear quadrupole resonance (E. Schempp and P. J. Bray), Mössbauer spectroscopy (N. N. Greenwood), molecular beam spectroscopy (C. R. Mueller) and, finally, electron diffraction in gases (S. H. Bauer).

The volume is well edited, the nomenclature and symbolism being consistent throughout, but it is disappointing that SI units and equations appear only (as alternatives to c.g.s. units) in Buckingham's chapter. What is difficult in books of this type is to establish amongst the authors a common view of the level and standard of the articles required. Here the editors have been less successful: articles range from excellent introductions, written with authority, to reviews, some thorough, some not and some which assume so much prior knowledge as to make them useful to research workers in the field only.

Although the articles do not attempt to be encyclopaedic, they should summarize the state of development of each topic. The n.m.r. chapter, which makes the subject seem unduly complex, fails to deal with solid state studies and considers but perfunctorily studies of partially orientated molecules (it also gives the symbol " $J$ " a novel meaning). The e.s.r. chapter takes no account either of gaseous species or of neutral radicals in solution; optical methods only are discussed in the study of the spectra of radicals: and no experimental evidence is given for the breakdown of the Born-Oppenheimer approximation, although the theory of the effects is discussed with insight. The chapter on molecular beam spectroscopy lacks detail. I recommend the chapters by Costain, Buckingham, Shimanouchi, Schempp and Bray and Greenwood ; the chapter by King includes a very clear introduction to Group Theory.

At a third of the price, this volume could be on every undergraduate's bookshelf, alongside a good book on magnetic resonance. As it is, all readers should leave its purchase to the richer libraries.

K. A. McLauchlan

\section{Geochemical Data}

Handbook of Geochemistry. Volume II/2. Executive editor: K. H. Wedepohl. Editorial board: C. W. Correns, D. M. Shaw, K. K. Turekian and J. Zemann. Pp. iv +667 . (SpringerVerlag: Berlin and New York, 1970.) Loose-leaf binder, 212 DM; $\$ 58.30$.

MY chief criticism of the first loose-leaf instalment of volume two of the Handbook of Geochemistry was that all material for an element had not been collected before publication of that particular chapter. The appearance of part two hardly eases the frustration engendered by this continuing procedure. Only three further chapters (iron, tin and mercury) have been completed to be added to the finished contributions on carbon, scandium, germanium and rhenium. Partial data for twelve new chapters are now published, but there are still twenty-five elements (including nitrogen, silicon, nickel and copper) for which there is yet no information.

On the production side SpringerVerlag will not win friends with this second instalment. First, the price of the new part (slightly under nine cents per page, as against less than five and a half cents for volumes one and two, part one) has risen at a rate that seems excessive, even in these days of cost inflation. Are subsequent instalments to suffer similar price increases of almost sixty per cent over twelve month periods? Second, surely the publishers could have ensured the same positioning for the punch holes of the pages in the two published parts. So poor is the positioning in the separate parts that when the chapters are arranged in their correct element order, there is a five millimetre variation in the registration of the page margins. Furthermore, thirty-eight sheets are punched on the wrong vertical margin so that the chapter "Yttrium and the Lanthanides" has to be read from back to front, unless it is removed from the file.

The scope of the work, its high standard of text and figure presentation, and the extensive literature coverage are still matters for editorial congratulation. Publication of part two on schedule is also commendable.

DunCAN MURChison 